\title{
Der Leichnam in Film, Literatur und Kunst
}

Dass wir sterben müssen, wissen wir allein deswegen, weil andere sterben. Wir erleben den Tod im Leichnam des anderen. Dieser ist für uns Hinterbliebene materiell die äußerste Repräsentation des Todes - eine temporäre Repräsentation, die ihrerseits dem Verfall preisgegeben ist. Die Konfrontation mit realen Leichnamen allerdings ist heutzutage in unseren Breitengraden $\mathrm{zu}$ einer Leerstelle geworden, wir leben in einer leichnamsfreien Kultur.

Jahr für Jahr sterben weltweit aktuell ca. 55 bis 6o Millionen Menschen; in der Schweiz sind es ca. 68.0oo, in Österreich ca. 83.00o, in Deutschland ca. 940.00o. Seit der Covid-19-Pandemie haben sich diese Zahlen in der Schweiz und Österreich um einige tausend, in Deutschland um einige zehntausend Tote erhöht. Jede einzelne tote Person wird besprochen und betrauert. Man bestattet sie, man kümmert sich um ihren Leichnam - zwar industrialisiert, arbeitsteilig, entfremdet, aber man kümmert sich. Dennoch ist es heute in westlichen Ländern ohne Weiteres möglich, dass man sehr alt wird, ohne je einen Leichnam gesehen zu haben. Der Grund dafür liegt in der professionellen Versorgung von Toten, die von den Gesundheits- und Sicherheitsbehörden gewährleistet wird. Jeder Leichnam, egal ob im privaten Raum, im Krankenhaus oder an einem anderen Ort, gerät auf geregelte Weise in Obhut. Bei Todesfällen im öffentlichen Raum werden Leichname auf den Boden gelegt, in Erdnähe gebracht und zugedeckt; anschließend verlädt man sie in Autos und transportiert sie in Gebäude, ihre rasche (Ver-)Bergung und Versorgung durch professionelle Kräfte ist garantiert. Die Corona-Krise erforderte aufgrund des plötzlichen Anstiegs von Toten an verschiedenen Orten zusätzliche behördliche Maßnahmen der Totenversorgung (die Militärlastwagen in Bergamo, die die Särge abtransportierten; die langen weißen Kühlwagen in New York; die zu Notfallleichenhallen umfunktionierten Madrider Eishallen; die Erstellung temporärer Leichenzelte in der Westschweiz; Angehörige der Armee und der Feuerwehr, die Bestattungsunternehmen unterstützten). Diese Maßnahmen trugen dazu bei, die Versorgung der Leichname weiterhin zu gewährleisten, und sie führten insbesondere auch zu einer Sichtbarkeit dieser Versorgung, die in weniger krisenhaften Zeiten kaum gegeben ist.

Außerhalb der Gesundheitseinrichtungen allerdings wurde eine allgemeine Sichtbarkeit des Leichnams durch die Pandemie nicht erhöht. Der tote Körper ist aus dem Alltagsbewusstsein nach wie vor weitgehend verschwunden, auch seine Abbildung scheint tabuisiert. Dies manifestiert sich unter anderem 
dann, wenn die öffentliche bildliche Darstellung von Leichen medienethisch verhandelt wird. In vielen Staaten gibt es einen Presserat, der dem Publikum sowie Medienschaffenden bei ethischen Bedenken als Beschwerdeinstanz zur Verfügung steht. Nach Unfällen und Naturkatastrophen sind diese Instanzen kontinuierlich mit Beschwerden seitens des Medienpublikums befasst, wenn Leichen in einer als unzumutbar empfundenen Weise gezeigt werden. Dies war etwa der Fall bei veröffentlichten Bildern von Leichnamen am thailändischen Strand nach dem Tsunami von 2004, bei der Massenpanik während der Loveparade 2010 in Duisburg, beim zweijährigen Alan Kurdi, der 2015 tot am türkischen Strand angespült wurde und dessen Bilder um die Welt gingen, oder beim Anschlag auf die Synagoge in Halle 2019. Auch das Genre der Kriegsfotografie führt immer wieder zu entsprechenden Diskussionen. Meist wird dabei die sensationelle Darstellung der Leichen beanstandet, wenn diese etwa nicht zugedeckt, gar mit entblößtem Unterleib daliegen oder verunstaltet sind. Die Beschwerden betreffen die Wahrung der Menschenwürde, das Persönlichkeitsrecht sowie den Schutz der Privatsphäre und werden dabei mehrheitlich gutgeheißen.

Die Leiche ist, obschon noch körperlich, schon das Andere des Lebens, das durch den toten Körper hereinzubrechen droht. Die Freisetzung dieses Anderen gilt es, wie der Kulturwissenschaftler Thomas Macho festhält, um jeden Preis zu vermeiden: „Die Leiche schafft einen Raum der Asozialität; einen Raum, dessen Grenzen möglichst rasch festgelegt werden müssen, um den eigentlichen Lebensraum zu schützen. ${ }^{1}$

In unserer Gegenwart ist die Konfrontation mit realen Leichnamen zu einer kulturellen Leerstelle geworden. Angesichts dieser Leerstelle und angesichts des Tabus der medialen Abbildung wird in diesem Kapitel aufgezeigt, welche Strategien im Umgang mit toten Körpern sich gegenwärtig in Film, Literatur, bildender Kunst, Fotografie und Performance manifestieren.

Dabei gilt es zunächst zu unterscheiden zwischen der Darstellung von fiktiven und der Darstellung von realen Leichnamen. Die filmische Unterhaltungsindustrie präsentiert beständig Leichname, die fiktiv und für den Bildschirm zurechtgeschminkt sind; ähnlich verfahren Kriminalromane bei immer neuen Schilderungen von fiktiven Leichnamen. In autobiografischer Literatur hingegen, in der sich Schriftsteller:innen autobiografisch mit dem Verlust ihrer verstorbenen Kinder, Eltern oder Partner:innen auseinandersetzen, taucht der tote Körper nur sehr selten auf: Die Beschreibung des Leichnams wird in der Regel ausgespart.

1 Thomas Macho: „Die Wiederkehr der Toten nach der Moderne“. In: Six Feet Under. Autopsie unseres Umgangs mit Toten. Bielefeld, Leipzig 2006, S. 19. 
In der bildenden Kunst findet seit etwa einem Jahrzehnt eine verstärkte Auseinandersetzung mit dem realen Leichnam statt, nachdem dieser bereits im letzten Drittel des 2o. Jahrhunderts vermehrt ins Blickfeld dieser Disziplin geraten war. $^{2}$ Von der entsprechenden gegenwärtigen Aktualität zeugt die große kulturhistorische Ausstellung Das letzte Bild. Fotografie und Tod, die 2018-2019 im C/O Berlin, dem Berliner Ausstellunghaus für Fotografie, stattfand. Sie zeigte über 400 Exponate von den Anfängen der Fotografie bis zur Gegenwart: Bilder von Toten in Kriegszeiten, anonyme tote Opfer von Gewaltverbrechen sowie sterbende und tote Menschen in Privaträumen. ${ }^{3}$ In jüngster Zeit lassen sich in der Malerei, Fotografie und Performance zwei im Grundsatz verschiedene Darstellungen von Leichnamen unterscheiden: einerseits Abbildungen von geliebten toten Personen, von denen es sich zu verabschieden gilt, andererseits Darstellungen von unbekannten Leichnamen aus Leichenhallen, die die Sterblichkeit an sich thematisieren.

\section{Der fiktive Leichnam}

Eine filmgeschichtlich herausragende, vielfach preisgekrönte Inszenierung des Leichnams bietet dieUS-amerikanischeFernsehserie Six Feet Under-Gestorben wird immer (2001-2005), die den toten Körper exzessiv ins Bild brachte. Die Serie schildert das Alltags- und Berufsleben der Bestatterfamilie Fisher. Im Keller des Familienhauses in Los Angeles befinden sich die Apparaturen und Konservierungsstoffe, mittels derer man die Leichname behandelt und einbalsamiert; ein Stockwerk höher, ebenerdig, liegt der Abdankungsraum, wo die Toten im offenen Sarg aufgebahrt werden, und wiederum ein Stockwerk höher spielt sich das Familienleben der Fishers ab.

In langen Einstellungen werden in dieser Serie immer wieder Leichname ins Bild gerückt. Oftmals stehen Mitglieder der Familie Fisher und andere

2 Vgl. den Ausstellungskatalog Zum Sterben schön? Der Tod in der Kunst des 20. Jahrhunderts (2007), der Figurationen des Leichnams gegen Ende des 20. Jahrhunderts präsentiert. Siehe auch die interdisziplinären Bände zum Leichnam, die seit 2010 in der Reihe Todesbilder (Campus Verlag) erschienen sind: Dominik Groß, Jasmine Grande (Hg.): Objekt Leiche. Technisierung, Ökonomisierung und Inszenierung toter Körper. Frankfurt/M. 2010; Brigitte Tag, Dominik Groß (Hg.): Der Umgang mit der Leiche: Sektion und toter Körper in internationaler und interdisziplinärer Perspektive. Frankfurt/M. 2010; Dominik Groß, Julia Glahn, Brigitte Tag (Hg.): Die Leiche als Memento mori: Interdisziplinäre Perspektiven auf das Verhältnis von Tod und totem Körper. Frankfurt/M. 2010.

3 Dabei handelt es sich sowohl um Kunstfotografien als auch um dokumentarische Fotos aus medizinischen und kriminalistischen Archiven. Siehe den gleichnamigen Katalog: Das letzte Bild: Fotografie und Tod / Photography and Death: The Last Image. Hg. von Felix Hoffmann und Friedrich Tietjen. Leipzig 2018. 


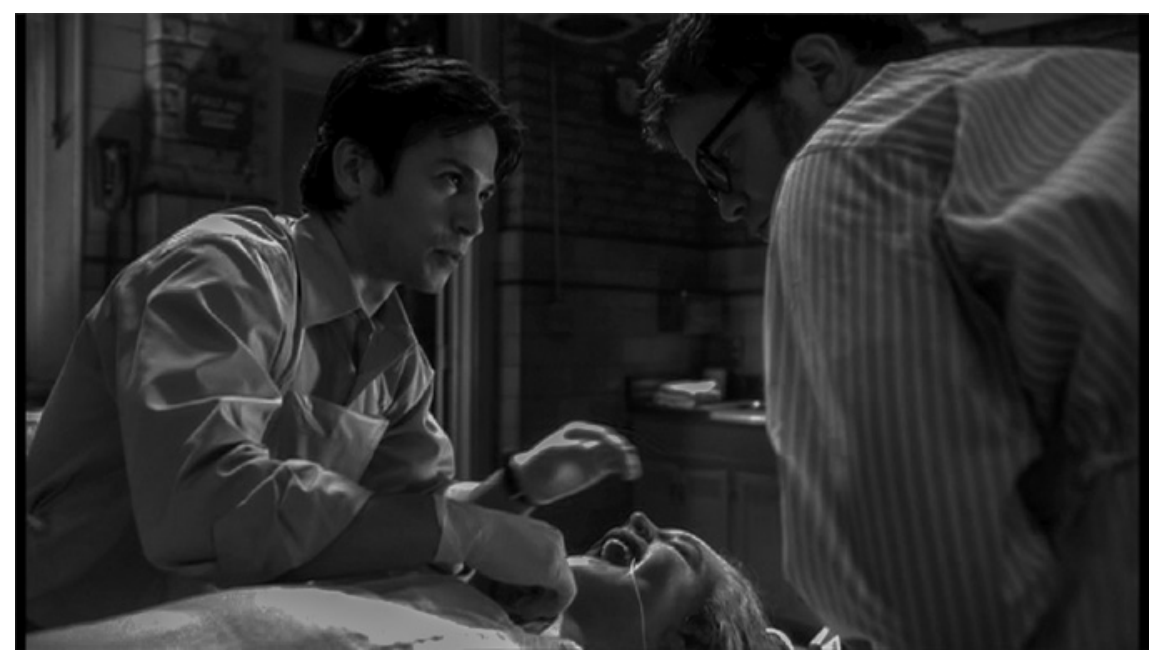

Abb. 12 „Parallel Play“. Six Feet Under. HBO, USA 2008. Fernsehserienepisode. oo:12:40.

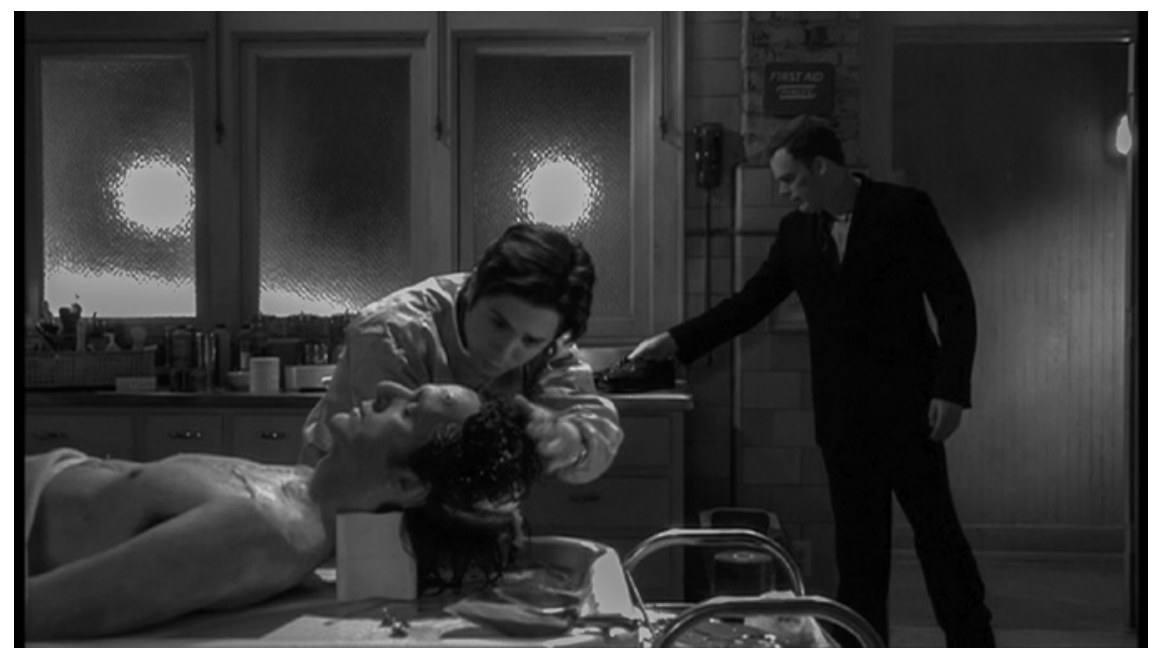

Abb. 13 „Terror Starts at Home“. Six Feet Under. HBO, USA 2008. Fernsehserienepisode. oo:11:00.

Beteiligte um sie herum, unterhalten sich, sitzen neben ihnen und führen imaginäre Gespräche mit den Verstorbenen (vgl. Abb. 12 und 13).

Dabei bemüht sich die TV-Produktion, die Leichen realitätsnah $\mathrm{zu}$ präparieren, indem sie sich an den hohen US-amerikanischen Standards der Thanatopraxie ausrichtet, d. h. der Lehre und Kunst der hygienischen Totenversorgung. Mithilfe von Schläuchen wird das Blut durch konservierende 
Flüssigkeiten ausgetauscht, die Gesichtshaut wird neu eingefärbt, Implantate werden in die Wangen gesteckt. All dies ist respektvoll dargestellt, die Familie Fisher tritt den Leichnamen ehrerbietig und professionell gegenüber. Für das Publikum schwer zumutbare Bilder wie etwa ein stark verunstalteter Schädel oder durch Unfälle versehrte Körper werden nur selten gezeigt. Hier gibt es keine Leichenbilder, die Anlass zu Beschwerden geben. Vielmehr wird eine würdevolle Totendarstellung inszeniert, die sich gleichsam normativ nach außen kehrt.

Elisabeth Bronfen legte in ihrer Studie über das Motiv des weiblichen Todes in der Literatur des 18. und 19. Jahrhunderts dar, wie durch die künstliche Stilisierung der Leiche zur "schönen Leiche“ das drohende Chaos angesichts von Tod und Erotik außen vor gehalten und die gesellschaftliche Stabilität garantiert werden kann. ${ }^{4}$ Analog dazu sucht heute die Thanatopraxie die Imagination der schönen Leiche mit neusten Techniken der Einbalsamierung zu realisieren. In Six Feet Under wird diese filmästhetisch simuliert, da die Leichen nicht real sind. Jedoch lobte die US-amerikanische Bestatterszene den dargestellten Umgang mit Leichnamen als sehr realistisch. Die Serie hat den Beruf des Bestatters in der populären Filmwelt erstmals salonfähig erscheinen lassen.

Daran schließt die ebenfalls sehr erfolgreiche Schweizer TV-Serie Der Bestatter (2013-2019) an, in deren Zentrum ebenfalls eine Bestatterfirma steht. Auch hier kommt es immer wieder zu Szenen, in denen der Bestatter lange am offenen Sarg verweilt (vgl. Abb. 14 und 15). Konstitutiv für die Erzählung in dieser Serie ist die narrative Kombination von Bestattung und Kriminalgeschichte, personell angelegt im Protagonisten Conrad, der vor seiner Bestatterkarriere leitender Ermittler bei der Polizei war. Als Bestatter führt er insbesondere (Natur-)Bestattungen durch ${ }^{5}$, was die Schweizer Bischofskonferenz nach der ersten Staffel zu der Kritik veranlasste, dass „die Dimension der Kirche konsequent ausgeblendet" werde. ${ }^{6}$

Der am weitesten verbreitete ,Film-Leichnam' aber ist der ermordete Leichnam in Kriminalfilmen, der den Ausgangspunkt der Erzählung und den Fokus für die Rekonstruktion des Mordes bildet. Seit den 196oer Jahren werden solche Filme fürs Fernsehen unablässig in Serie produziert. Eine Zäsur markiert dabei die um 2000 einsetzende TV-Karriere der Forensik, bei der der Leichnam als Textträger ausgiebig inszeniert wird: Er birgt Spuren des an ihm begangenen

4 Elisabeth Bronfen: Nur über ihre Leiche. Tod, Weiblichkeit und Ästhetik. München 1993.

5 Vgl. dazu Kap. 7, S. 122-123, sowie Corina Caduff: „Die alternative Schweizer Bestattungsszene (zum Bestatter)“. In: Kulturtipp 10 (2014), S. 32-33.

6 Vgl. den Artikel „Kirche sauer wegen ,Der Bestatter': Wo bleiben die Pfarrer?“ In: Blick, 28. Januar 2013. 


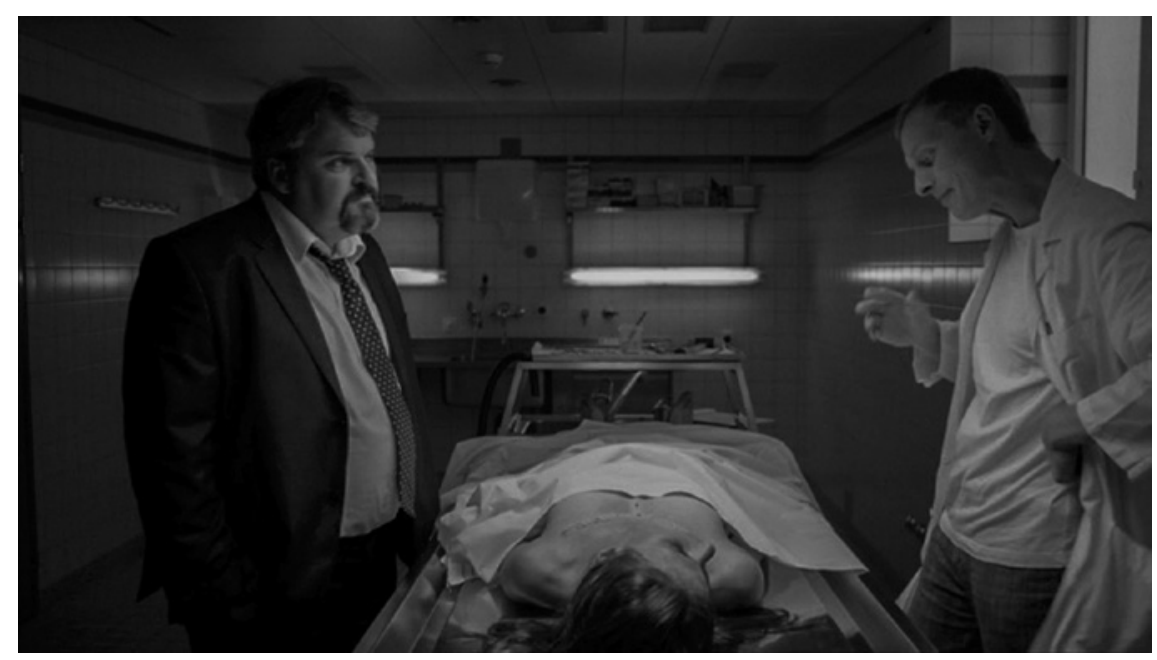

Abb. 14 „Schweres Erbe“. Der Bestatter. SRF, Schweiz 2013. Fernsehserienepisode. oo:21:28. Online unter: https://www.dailymotion.com/video/x6imagu (letzter Zugriff: 23.11.2021).

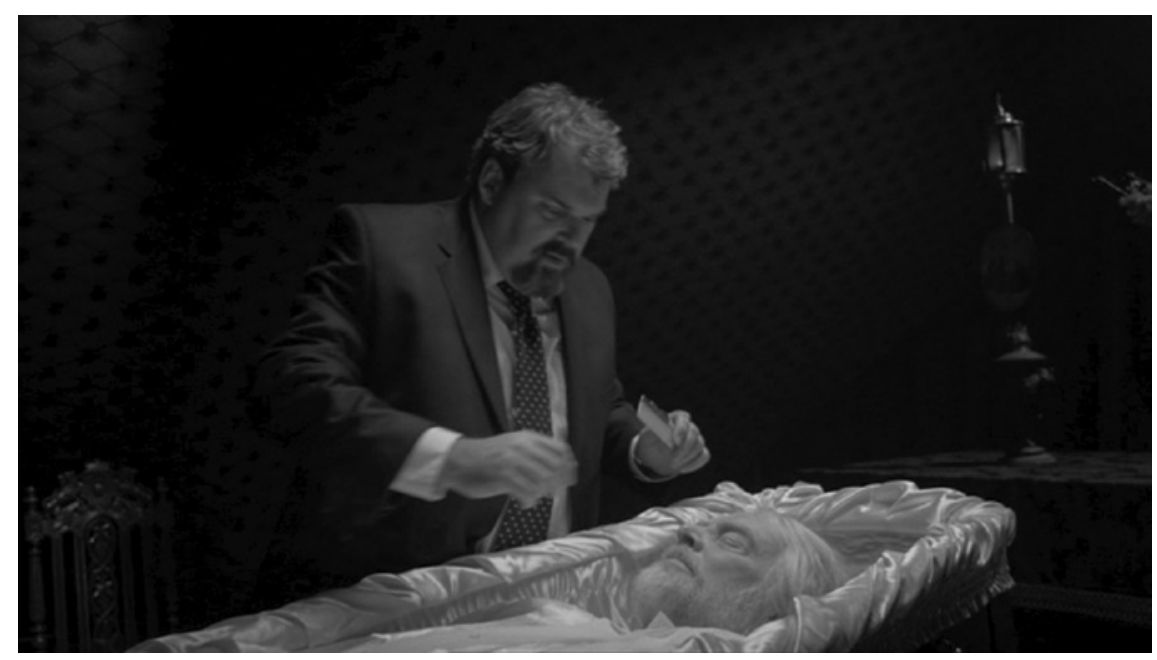

Abb. 15 „Schweres Erbe“. Der Bestatter. SRF, Schweiz 2013. Fernsehserienepisode. oo:o1:43. Online unter: https://www.dailymotion.com/video/x6imagu (letzter Zugriff: 23.11.2021). 
Verbrechens, die es zu lesen, zu interpretieren und zu erzählen gilt. Diese Karriere basiert insbesondere auf den US-amerikanischen Serien CSI (20002015), Bones (2005-2017) ${ }^{7}$, Navy CIS (2003-2020) oder der True-Crime-Serie Beweisstück A (2019ff.), in denen es wiederholt zu ausgiebigen erörternden Diskussionen angesichts der Leichen in der Pathologie kommt.

Analog zum Leichnam im Film-Krimi präsentieren auch literarische Krimis mannigfache fiktive Leichendarstellungen. Wie im Film steht auch hier der übel zugerichtete Körper im Zentrum, doch die Darstellungsmittel sind nun sprachlicher Art. Die folgenden Beispiele aus Kriminalromanen machen deutlich, dass in dem Genre ein offensichtlicher Druck nach immer neuen Ideen für die Zurichtung von Körpern besteht:

Ihr Blick heftete sich auf das, was am Haken des Flaschenzugs hing. Der Fliegenschwarm, der den gut abgehangenen Leckerbissen umschwirrte, war so dicht, dass sie das Brummen in den Knochen zu spüren glaubte. Die Haut war abgezogen worden, sodass sie noch leichter an das rohe Fleisch herankamen, in dem es bereits von Maden wimmelte. Frost wich schwankend zurück und würgte. Der nackte Mann hing kopfüber von der Decke, die Fußknöchel mit orangefarbenem Nylonseil gefesselt. Wie bei einem Schweinekadaver im Schlachthaus hatte man ihm den Bauch aufgeschlitzt und sämtliche Organe entnommen. ${ }^{8}$

Es war selbst für Hartgesottene ein entsetzlicher Anblick. So etwas hatte Dupin während seiner gesamten Laufbahn noch nicht gesehen. Die Leiche war mit Fischabfällen übersät, Innereien, Mägen, Gedärmen, einem Gemisch aus allem halbwegs Flüssigen, das sich in der Tonne gesammelt hatte. Sogar ganze Fischstücke, Teile von Gräten und Fischschwänze klebten an der Frau. [...] Am Oberkörper hatte sich die schleimige Masse mit dem Blut der Frau vermischt. ${ }^{9}$

\begin{abstract}
Aber es war das, was unter den Brauen klaffte, was Mauras geschockten Blick auf sich zog. Beide Augenhöhlen waren leer. Der Inhalt war herausgeschält worden, sodass nur die blutigen Höhlen zurückblieben. Fassungslos starrte Maura auf die linke Hand der Frau. Auf das, was da wie zwei grausige Murmeln auf ihrer offenen Handfläche lag. ${ }^{10}$
\end{abstract}

Die drei Leichenbeschreibungen enthalten zwar Hinweise auf schockartige Momente bei den Betrachtenden - „entsetzlicher Anblick“, „Frost wich schwankend zurück und würgte“, "geschockt", „fassungslos" -, doch die Formulierungen unterstreichen eher die Innovation in der Darstellung

\footnotetext{
7 Vgl. dazu Tina Weber: Drop Dead Gorgeous. Representations of Corpses in American TV Shows. Frankfurt/M., New York 2011.

8 Tess Gerritsen: Der Schneeleopard. Ein Rizzoli-\&Isles-Thriller. München 2015, S. 31.

9 Jean-Luc Bannalec: Bretonische Flut. Kommissar Dupins fünfter Fall. Köln 2016, S. 11.

10 Tess Gerritsen: Blutzeuge. München 2017, S. 26.
} 
der Tötungs- bzw. Zurichtungsart. Denn im Allgemeinen zeichnen sich die ermittelnden Kriminalbeamten angesichts des Leichnams durch ihre Abgebrühtheit aus - wenig Regung, kaum Bestürzung, stattdessen sofort die immer gleichen Routinefragen.

Der fiktive Krimi-Leichnam dient primär der rekonstruierenden Erzählung, es geht um die Aufdeckung von Morden und Motiven, nicht um eine Verhandlung von Sterben und Tod an sich. Die Krimi-Leichen sind somit ein wesentlicher Bestandteil der Unterhaltungsindustrie. Während die Konfrontation mit realen Leichnamen aus unserem Alltag weitgehend verschwunden ist, umgibt uns der Unterhaltungssektor tagtäglich mit immer neuen fiktiven Toten. Die systematische Abdrängung des realen Leichnams aus dem Alltag hat eine kulturelle Leerstelle erzeugt, welche Filme und TV-Serien sowie auch literarische Kriminalromane übernommen und vereinnahmt haben: Sie bespielen und besetzen die Leerstelle unaufhörlich mit immer neuen Leichnamsbildern, die an die Stelle der Auseinandersetzung mit realen Leichnamen getreten sind.

\section{Schreiben über Tote: Leerstelle Leichnam}

In autobiografischen Texten der Gegenwartsliteratur befassen sich zahlreiche Schriftsteller:innen mit ihren verstorbenen Partner:innen, Kindern oder Eltern. Sie halten ihre Beziehungen und Erlebnisse mit den verlorenen geliebten Personen schriftlich fest und geben ihrer Trauer auf vielfältige Weise Ausdruck, sie suchen den Tod kommunizierbar zu machen und den Verlust schreibend zu bewältigen. Dabei setzen sie mannigfache Erinnerungen in Szene: Sie memorieren Gespräche, Unternehmungen und Positionierungen im familiären Kontext, sie heben die verstorbene Person im Text auf und leuchten die Beziehung zu ihr bis in hinterste Ecken aus - aber sie halten kaum inne beim Leichnam. Tatsächlich finden sich in solchen literarischen Trauerbüchern nur sehr wenige Beschreibungen von der Begegnung mit einem Leichnam. So wie wir gegenwärtig in einer leichnamsfreien Kultur leben, so präsentiert sich auch die autobiografische Gegenwartsliteratur, in der es um reale Tote geht, weitgehend leichnamsfrei.

Wo es dennoch zu entsprechenden Erwähnungen kommt, da ist meist eher vom organisatorischen Kontext die Rede und nicht vom Leichnam selbst: von der Identifizierung im Bestattungsinstitut, vom Transport, von Terminen, von der Beerdigung. In der Regel fallen keine Worte über ein Verweilen bei der verstorbenen Person, deren Antlitz wird nicht beschrieben. 
So reproduzieren literarische Trauerbücher die kulturelle Leerstelle, wie die folgenden Zitate deutlich machen. Diese sind Erzählpassagen entnommen, die um den Leichnam kreisen, ohne jedoch eine unmittelbare Anschauung des toten Körpers zu präsentieren. Die dazu eingesetzten erzählerischen Strategien variieren. Nur äußerst selten kommt die Anschauung der Leiche, wie beim letzten Beispiel aus Karl Ove Knausgårds autobiografischem Roman Sterben, direkt zur Sprache.

Lukas Bärfuss: Koala (2014)

Der preisgekrönte Roman Koala geht von einer existenziellen autobiografischen Erfahrung des Autors aus: 2011 nahm sich Lukas Bärfuss' Halbbruder (geb.1971) das Leben. Aufgewühlt, von Fragen getrieben, erkundet Bärfuss diesen Selbstmord auf eindringliche Art und Weise. Er selbst hat den Leichnam des Bruders nicht gesehen. Die Beschreibung des Leichnams erfolgt daher gleichsam sekundär: Der Erzähler sucht Spuren seines Anblicks in den Gesichtszügen der beiden Freunde, die den toten Bruder in der Badewanne gefunden haben.

An einem Tisch sass ein Mann, den ich seit Jahren nicht gesehen hatte. Er war jünger als der Hausbesitzer, und es erwies sich, dass sie gemeinsam die Wohnung des Toten betreten hatten und den Schrecken teilten, der von der frischen Leiche eines Freundes ausgeht. Aber es schien, als habe dieser Schrecken mit verschiedenen Griffeln in ihre Gesichter geschrieben und bei jenem, der am Tische saß, harte, wütende Zeichen hinterlassen, beim anderen aber, dem Hausbesitzer, weiche und erstaunte.

$[\ldots]$

Er hatte keinen Schmutz hinterlassen, sich deswegen in die Wanne gelegt, damit beim Tod austretende Körperflüssigkeiten umstandslos weggespült werden konnten und die Wohnung nicht verunreinigen würden. [...] Es schien, als habe mein Bruder Rücksicht bewiesen, indem er den Aufwand zur Entsorgung seiner Leiche auf die Reinigung einer Badewanne beschränkte, aber ich sah darin einen sarkastischen Kommentar zu den Ansichten der Reinlichkeit, die in jener Gegend vertreten wurden, dass die größte Zumutung eines Selbstmörders nicht sein Tod, sondern der Schmutz sei, den er hinterlässt. ${ }^{11}$

11 Lukas Bärfuss: Koala. Göttingen 2014, S. 15f. und 23 f. 
Meral Kureyshi: Elefanten im Garten (2015)

Meral Kureyshiwurde 1983 in Prizren (ehem.Jugoslawien, heute Kosovo) geboren und verbrachte dort ihre frühe Kindheit. Im Alter von zehn Jahren kam sie mit ihren Eltern und Geschwistern nach Bern. Ihr autobiografischer Erstlingsroman Elefanten im Garten handelt von der Schweiz als Immigrationsland. Hier stirbt ihr Vater. Nach seinem Tod wird er gemäß muslimischer Tradition in ein meterlanges weißes Leichentuch gehüllt und eingesargt. Die Abwendung vom Leichnam des Vaters erfolgt hier explizit: Die Tochter will ihn nicht sehen.

Die Männer, mit denen du in Bern in die Moschee gingst, haben deine Leiche gewaschen und sie in die sieben Meter [weißes Tuch] gehüllt. So wird das gemacht. Du wurdest in einen Sarg aus Holz gelegt, der zugenagelt wurde. Dein Gesicht würden deine Brüder durch eine Glasscheibe sehen wollen, hat der Hoca gesagt.

Ich wartete draußen, bis die Männer fertig waren, dann ging ich, bevor sie den Sarg wegtrugen. ${ }^{12}$

David Rieff: Tod einer Untröstlichen (2009)

David Rieff (geb. 1951), Sohn der US-amerikanischen Publizistin Susan Sontag (1933-2004), veröffentlichte ein Buch, in demer die letzten Lebensmonate seiner Mutter schildert. Susan Sontag erkrankte Anfang 2004 an Leukämie und starb Ende desselben Jahres. Rieff hebt vor allem hervor, wie sehr seine Mutter bis zum Schluss am Leben gehangen habe und wie sie nicht imstande gewesen sei, den bevorstehenden Tod zu akzeptieren und sich von ihrer Umgebung zu verabschieden. Er beschreibt den Moment ihres Sterbens, jedoch nicht das Antlitz der Toten.

Zuerst holte sie tief Luft; dann eine Pause von vierzig Sekunden, eine ungeheuer quälende, unendlich lang erscheinende Zeit, wenn man einen Menschen sterben sieht; dann ein weiterer tiefer Atemzug. Das ging noch ein paar Minuten weiter. Dann wurde aus der Pause Dauer, der Mensch hörte auf zu sein, und Stephen Niemer sagte: ,Sie hat uns verlassen:

$[\ldots]$

Also ließ ich den Leichnam meiner Mutter vom Kennedy Airport in New York nach Paris transportieren - mit dem gleichen Abendflug der Air France, den sie im Laufe ihres Lebens viele hundertmal genommen hatte. Es war unsere letzte gemeinsame Reise. ${ }^{13}$

12 Meral Kureyshi: Elefanten im Garten. Zürich 2015, S. 111.

13 David Rieff: Tod einer Untröstlichen. Die letzten Tage von Susan Sontag. München 2009 [engl. OA Swimming in a Sea of Death. A Son's Memoir, 2008], S. 148 und 156. 
Joan Didion: Das Jahr magischen Denkens (2006)

Die Autorin Joan Didion (geb. 1934) hatte mit ihrem Ehemann - John Gregory Dunne, auch er ein Schriftsteller - vierzig Jahre lang zusammengelebt. Am 30. Dezember 2003 starb er an einem Herzinfarkt. In ihrer autobiografischen Trauerstudie hält Joan Didion, wenngleich nur kurz, auch die Erinnerung an seinen Leichnam fest. Dabei konzentriert sie sich auf den Raum (Vorhänge, Kabine, Notaufnahme) und auf das Verschwinden von Schrammen im Gesicht. Weitere Wahrnehmungen kommen nicht zur Sprache.

Als ich ihn in der mit Vorhängen abgetrennten Kabine in der Notaufnahme des New York Krankenhauses gesehen hatte, war einer seiner Vorderzähne angeschlagen gewesen, ich nehme an, durch den Sturz, denn er hatte auch Schrammen im Gesicht. Als ich am nächsten Tag seinen Körper im Bestattungsinstitut identifizierte, fielen die Schrammen nicht auf. Ich begriff, dass der Leichenbestatter das Kaschieren der Schrammen gemeint hatte, als ich sagte, nicht einbalsamieren, und er sagte: „In diesem Fall werden wir ihn einfach waschen. ${ }^{14}$

Karl Ove Knausgård: Sterben (2011)

Der norwegische Autor Karl Ove Knausgård (geb. 1968) erzählt in seinem autobiografischen Roman Sterben eine qualvolle Vater-Sohn-Geschichte: Der Sohn leidet unter seinem herrischen Vater, welcher sich schließlich zu Tode säuft. Nachdem er gestorben ist, empfindet der Sohn neben der Trauer auch ein enormes Gefühl der Befreiung. Er geht zweimal in die Kapelle, um den Toten zu sehen, und schaut diesen so lange an, bis er begreift, dass es den Vater wirklich nicht mehr gibt. Eine solch ausführliche und dezidierte literarische Auseinandersetzung mit dem Leichnam ist außergewöhnlich.

Der Gedanke, dass ich dieses Gesicht zum ersten Mal ungehindert studieren konnte, war beinahe unerträglich. Ich hatte das Gefühl, mich an ihm zu vergreifen. Gleichzeitig verspürte ich einen unersättlichen Hunger, der verlangte, ihn immer weiter anzusehen, diesen toten Körper, der wenige Tage zuvor mein Vater gewesen war. Die Gesichtszüge waren mir vertraut, ich war mit diesem Gesicht aufgewachsen, und obwohl ich es in den letzten Jahren nur selten gesehen hatte, verging kaum eine Nacht, in der ich nicht von ihm träumte. Die Züge waren mir vertraut, nicht aber der Ausdruck, den sie angenommen hatten. Der dunkle, gelb gefärbte Teint und die verlorene Elastizität der Haut

14 Joan Didion: Das Jahr magischen Denkens. Berlin 2006 [engl. OA The Year of Magical Thinking, 2005], S. 23. 
ließen das Gesicht aussehen, als wäre es aus Holz geschnitzt. Dieses Holzschnittartige verhinderte jegliches Gefühl von Nähe. Ich sah keinen Menschen mehr, sondern etwas, das einem Menschen ähnelte. Gleichzeitig war er aus unserer Welt gekommen, und was er in dieser gewesen war, existierte in mir weiter, lag wie ein Schleier aus Leben über dem Toten..$^{15}$

\section{Totenfotografie: Das Zeigen von toten Geliebten}

Die Totenfotografie war in der zweiten Hälfte des 19.Jahrhunderts ein anerkanntes Auftragsgenre. Vorläufer waren die seit dem Altertum bekannten Totenmasken sowie das gemalte Totenporträt, welches in der Renaissance aufkam: Zunächst wurden geistliche Würdenträger und Adlige porträtiert, später auch Bürgerliche. Das gemalte Totenporträt erreichte, gleichzeitig mit der Totenfotografie, im 19. Jahrhundert seinen Höhepunkt. Mit verschärften Hygienebestimmungen jedoch, die Ende des 19. Jahrhunderts wegen Infektionsgefahr zu Verboten der Totenfotografie in den Städten führten, sowie auch mit der zunehmenden Industrialisierung des Bestattungswesens sind die Genres wieder verschwunden. ${ }^{16}$

Als kunstgeschichtliche Urszene des ,Zeigens von toten Geliebten' können Ferdinand Hodlers Bilder der sterbenden und schließlich toten Valentine Godé-Darel gelten. Godé-Darel war die Geliebte des Malers und stand ihm ab 1908 Modell. Als sie einige Jahre später an Krebs erkrankte, bannte der Künstler ihren monatelangen Krankheits- und Sterbeprozess in rund siebzig Bildnisstudien und Porträts (1914/15), und auch ihre Leiche diente ihm als Modell für verschiedene Studien (vgl. Abb. 16 bis 20$).{ }^{17}$

Die Bilder riefen in den 1980er- und 9oer-Jahren Kritik aus feministischer Perspektive hervor. Hodler wurde vorgeworfen, dass er den zunächst kranken und dann toten weiblichen Körper für seine Kunstgewinnung missbraucht habe. Insbesondere die Schriftstellerin Erica Pedretti kritisierte solche

15 Karl Ove Knausgård: Sterben. München 2011 [norw. OA Min kamp. Første bok, 2009], S. 295f.

16 Siehe Katharina Sykora: Die Tode der Fotografie I. Totenfotografie und ihr sozialer Gebrauch. München 2009, insbes. S. 131-146; Le dernier portrait. Musée d'Orsay. Katalog der Ausstellung vom 05. März bis 26. Mai 2002. Paris 2002.

17 Siehe Hodlers Darstellungen von Valentine Godé-Darel im Ausstellungskatalog Ein Maler vor Liebe und Tod. Ferdinand Hodler und Valentine Godé-Darel. Ein Werkzyklus 1908-1915 von Jura Brüschweiler, Zürich 1976. Die Bilder können online eingesehen werden z. B. unter: https://www.ferdinand-hodler.ch/hodler.aspx [>Band 2, Bildnisse; >Katalog Band 2 öffnen] (letzter Zugriff: 23.11.2O21). 


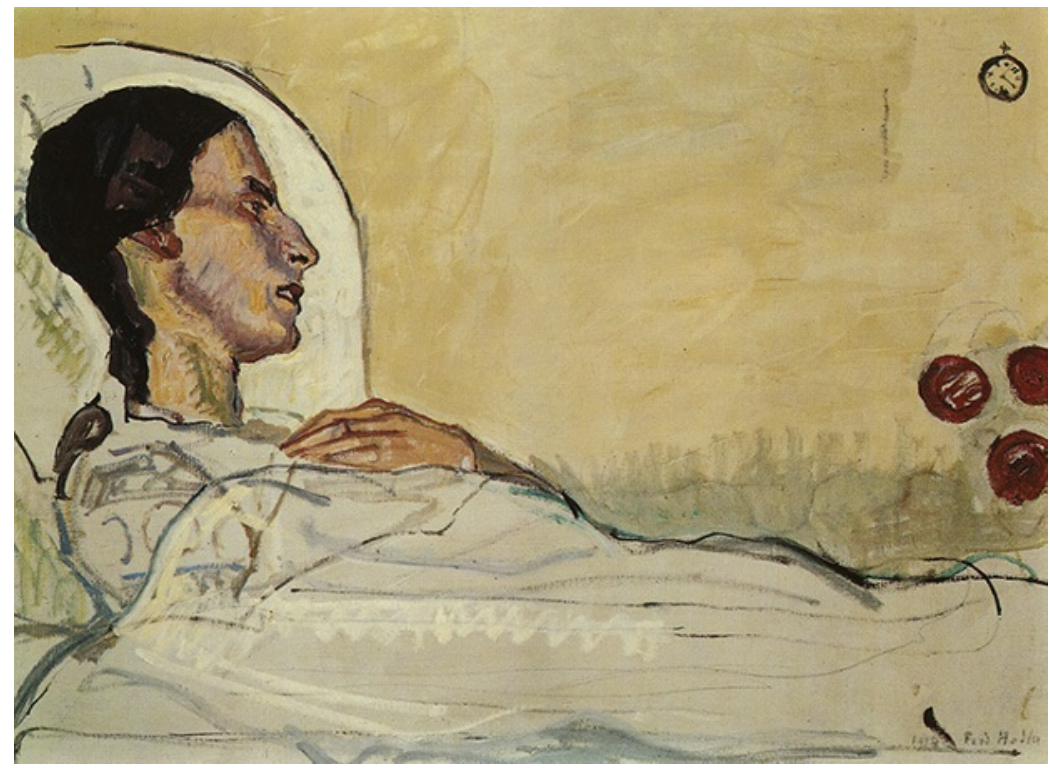

Abb. 16 Ferdinand Hodler: Die kranke Valentine Godé-Darel im Bett, mit Uhr und Rosen, 1914. Öl auf Leinwand, $63 \mathrm{~cm} \times 86 \mathrm{~cm}$, Privatbesitz. In: Jura Brüschweiler: Ein Maler vor Liebe und Tod. Ferdinand Hodler und Valentine Godé-Darel. Ein Werkzyklus 19o8-1915. Zürich 1976, S. 122.

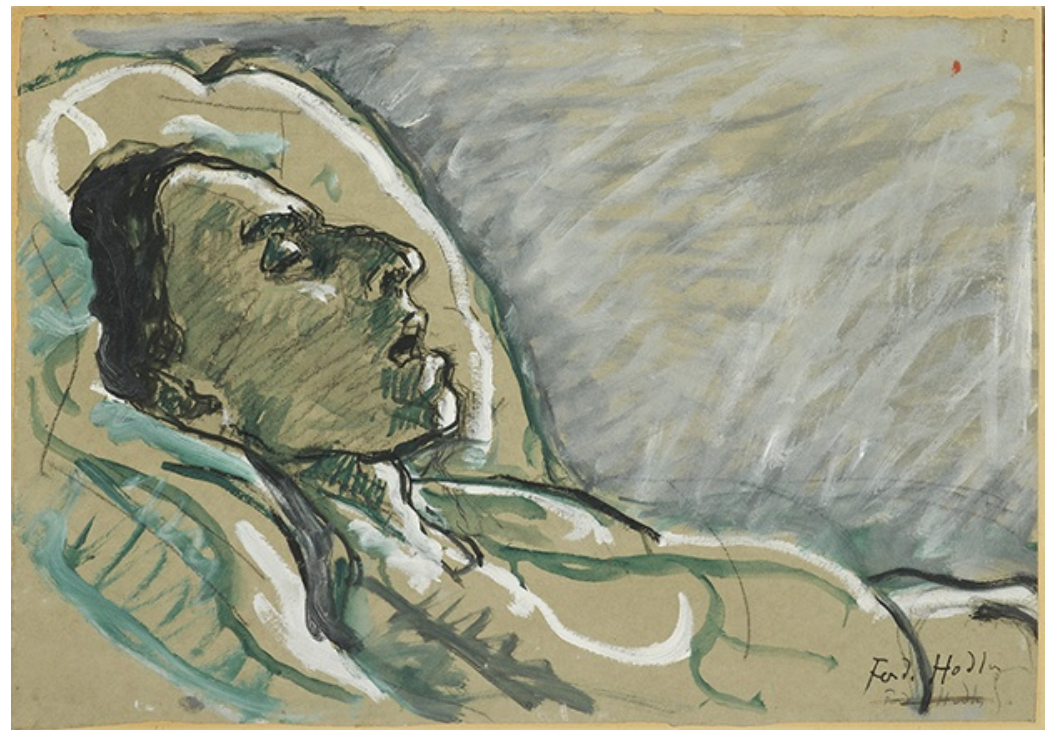

Abb. 17

Ferdinand Hodler: Die sterbende Valentine Godé-Darel, Rechtsprofil, 1915. Gouache, Öl und Kohle auf Papier, auf Karton aufgezogen, $37 \mathrm{~cm} \times 5^{2} \mathrm{~cm}$. Fotografie: Flora Bevilacqua, Musée d'Art et d'Histoire, Genf. 

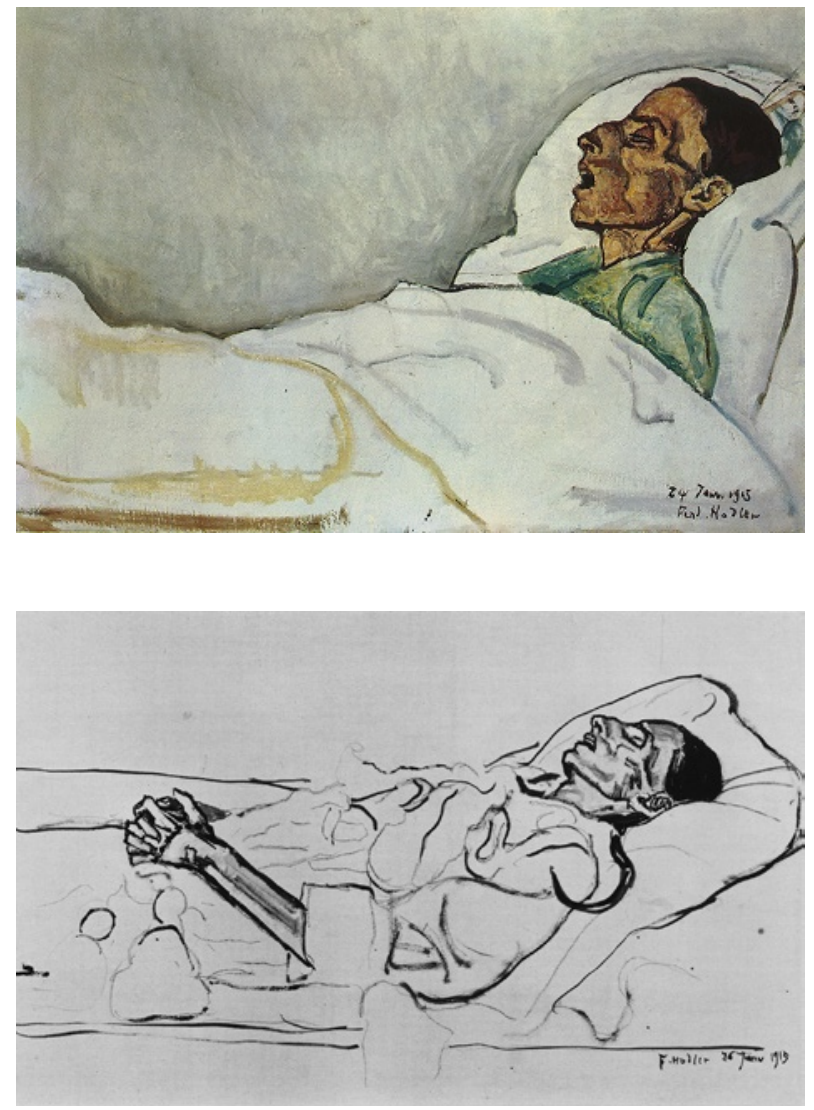

Abb. 18

Ferdinand Hodler: Die

sterbende Valentine

Godé-Darel, Halbfigur im

Linksprofil, 24. Januar

1915. Öl auf Leinwand,

$60,5 \mathrm{~cm} \times 9 \circ, 5 \mathrm{~cm}$,

Kunstmuseum Basel. In: Jura Brüschweiler: Ein Maler vor Liebe und Tod.

Ferdinand Hodler und

Valentine Godé-Darel.

Ein Werkzyklus 1908-1915.

Zürich 1976, S. 157.

Abb. 19

Ferdinand Hodler:

Die tote Valentine

Godé-Darel, 26. Januar

1915. Bleistift, Öl auf

Papier, 39,5 cm × $64 \mathrm{~cm}$,

Kunstmuseum Basel. In:

Jura Brüschweiler: Ein

Maler vor Liebe und Tod.

Ferdinand Hodler und

Valentine Godé-Darel.

Ein Werkzyklus 19o8-1915.

Zürich 1976, S. 159.

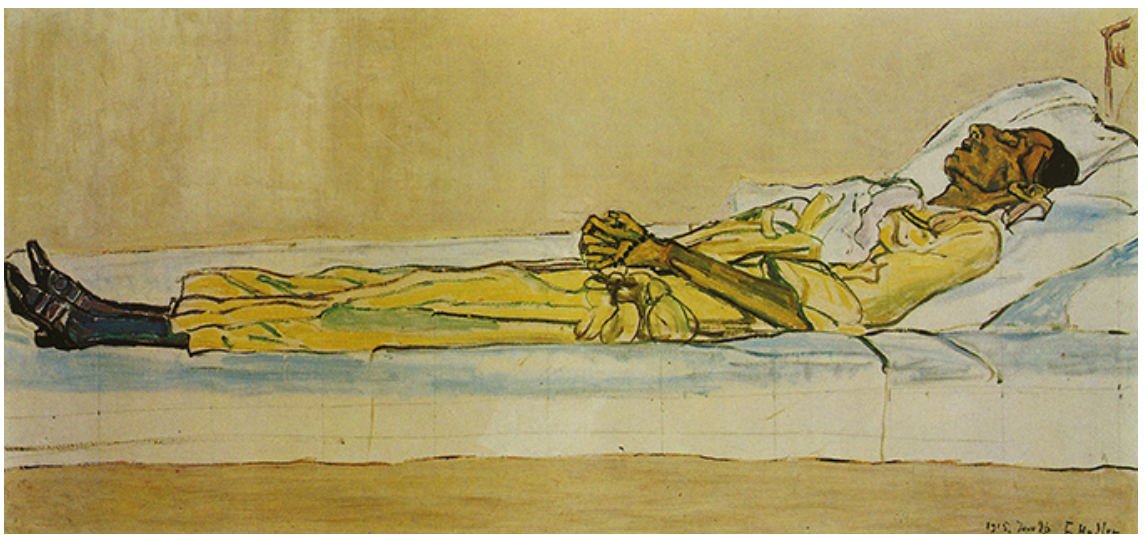

Abb. 20

Ferdinand Hodler: Die tote Valentine Godé-Darel, 26. Januar 1915, Öl auf Leinwand, 6 o $\mathrm{cm} \times 124 \mathrm{~cm}$, Museum der Stadt Solothurn. In: Jura Brüschweiler: Ein Maler vor Liebe und Tod. Ferdinand Hodler und Valentine Godé-Darel. Ein Werkzyklus 1908-1915. Zürich 1976, S. 161. 
Kunstverfertigung in ihrem Roman Valerie oder Das unerzogene Auge (1986): Das todkranke Modell spricht hier als Ich-Erzählerin aus, dass es bei den Bildern nicht um sie als Person gehe, sondern nur um die Kunst des Mannes: „Sobald er zu zeichnen anfängt [...], bin ich für ihn nicht mehr vorhanden." ${ }^{18}$

Beispiele aus der Gegenwart zeigen nun aber Künstlerinnen, die sich ihrerseits über geliebte tote Personen beugen, um sie zu fotografieren, und die auf diese Weise selbst als Produzentinnen von Totenbildern agieren. So erstellte die bekannte US-amerikanische Kunstfotografin Annie Leibovitz eine Totenfotografie ihrer langjährigen Gefährtin, der bereits genannten Susan Sontag. Das Foto, seitlich und von einem erhöhten Standpunkt aus aufgenommen, zeigt die aufgebahrte Sontag in einem knöchellangen Kleid von Fortuny, das Leibovitz als Totengewand ausgewählt hatte. Die Fotografin publizierte zwanzig kleinformatige, in weichem, gelb-goldenem Licht gehaltene Ausschnitte dieses Fotos, die verschiedene Ausschnitte des toten Leibes zeigen: das Gesicht, den Oberkörper, die übereinandergelegten Hände, die Beine, die Schuhe ${ }^{19}$ (vgl. Abb. 21 bis 23).

Auf diese Bilder verweist David Rieff in seinem Buch lediglich zweimal, kurz und unfreundlich. Er kritisiert die „poppigen Bilder vom Tod einer Prominenten“, und postuliert, ohne dies näher zu erläutern, dass die Bilder seine Mutter „postum erniedrigen“. ${ }^{20}$ Eine kontextualisierende Verortung seines eigenen Schreibens über das Sterben seiner Mutter erfolgt dabei nicht.

Ein weiteres Beispiel stellt das Fotobuch der Schweizerin Elisabeth Zahnd Legnazzi dar, deren Tochter Chiara 2000 im Alter von fünf Jahren an einem Hirntumor starb. Die Mutter und Fotografin dokumentierte die letzten Monate ihrer kranken, sterbenden und schließlich toten Tochter, und veröffentlichte

18 Erica Pedretti: Valerie oder Das unerzogene Auge. Frankfurt/M. 1986, S. 11f.

19 Annie Leibovitz: A Photographer's Life. 1990-2005. New York 2006, o.S. - Auch andere Künstler:innen fotografier(t)en geliebte tote Personen, so zum Beispiel der Finne Kimmo Metsärantas, der 2014 Fotografien des Leichnams seines Großvaters mit einem kurzen Begleittext unter dem Titel „Ich habe meinen toten Großvater fotografiert“ im Internet veröffentlichte. Analog zum Umgang von Annie Leibovitz mit der Totenfotografie von Sontag präsentiert auch er eine Totale des aufgebahrten Leichnams sowie verschiedene Porträtfotos des Gesichts und Nahaufnahmen der geschlossenen Augen und übereinandergelegten Hände. Online unter: https://www.vice.com/de/article/ex8pa7/fotografien-von-meinemgrossvater-kurz-nachdem-er-verstarb-946 (letzter Zugriff: 23.11.2021). Vgl. hierzu auch den japanischen Künstler Nuboyoshi Araki, der seine Ehefrau über Jahrzehnte hinweg fotografierte, begonnen bei den Flitterwochen 1971 bis hin zu ihrem Tod 1990: Nuboyoshi Araki: The Sentimental Journey 1971-2017. Tokyo 2017. Online unter: https://vimeo.com/237749738 (letzter Zugriff: 23.11.2021).

20 David Rieff (2009): Tod einer Untröstlichen. Die letzten Tage von Susan Sontag. München 2009, S. 135; vgl. auch den Hinweis auf Leibovitz, S. 62. 


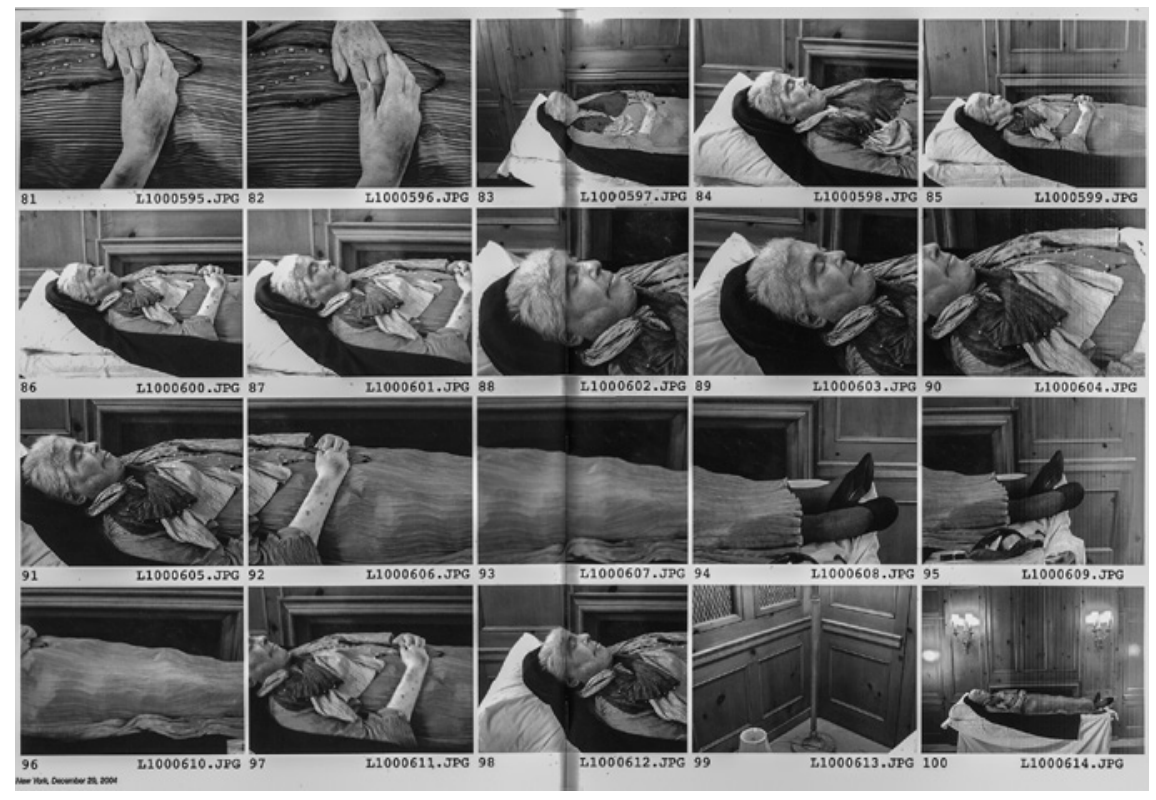

Abb. 21 Annie Leibovitz: „New York, December 29 (Susan Sontag), 2004“. In: Dies.: $A$ Photographer's Life. 1990-2005. New York 2006, o.S. 

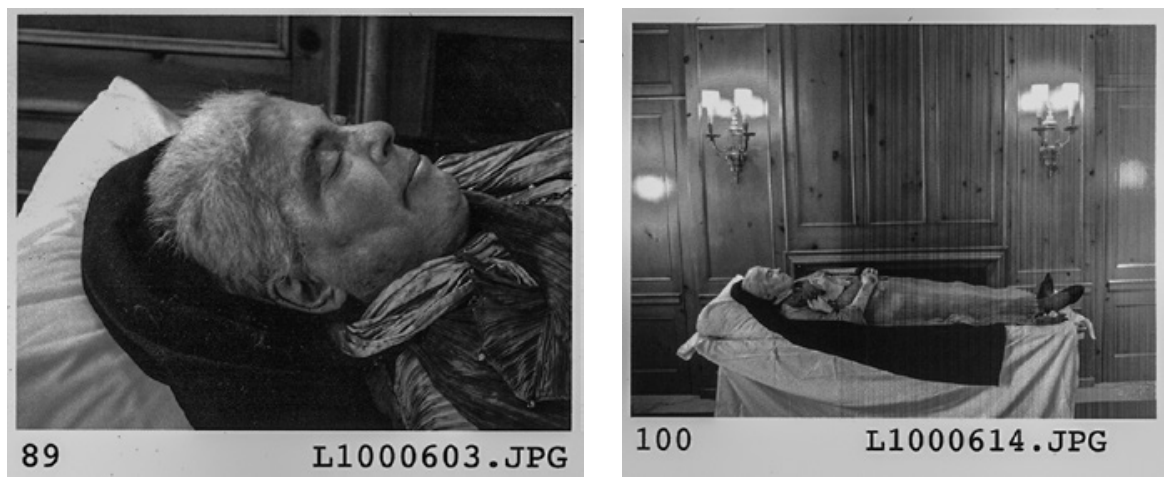

Abb. 22 bis 23

Annie Leibovitz: „New York, December 29 (Susan Sontag), 2004“. In: Dies.: A Photographer's Life. 1990-2005. New York 2006, o.S.

neun Jahre später ein Buch mit über fünfzig großformatigen Bildern. ${ }^{21}$ Diese zeigen Chiara im Bett liegend, auf Kissen und Decken gebettet. Sämtliche Fotografien sind, ähnlich wie bei Leibovitz, in weichen Pastellfarben gehalten, die einen milden Eindruck vermitteln. Bei der Veröffentlichung der Bilder sei es ihr, so Zahnd Legnazzi, insbesondere darum gegangen, den Sterbeprozess zu enttabuisieren. Wie früher Hodler wurde auch sie mit dem Vorwurf konfrontiert, dass es sich bei ihren Bildern um Kunstausbeutung handle; so fragte eine Journalistin, ob sie nicht „als Künstlerin Profit aus dem Sterben ihres Kindes“ gezogen hätte. ${ }^{22}$

Wenn Künstler:innen unmittelbar mit dem Tod konfrontiert sind, sei es, dass jemand in ihrer nächsten Umgebung stirbt oder dass sie selbst schwer erkranken, dann tun sie, was sie immer schon getan haben: Sie malen oder fotografieren oder schreiben und machen somit das, was sie am besten können, sie üben ihren Beruf aus. Es ist ihre Art, sich mit dem Tod auseinanderzusetzen, ihn zu berühren, ihn darstellbar zu machen, und damit auch der eigenen Trauer einen Ausdruck zu geben und eine Erinnerung an die Toten zu schaffen.

So machen Fotograf:innen Bilder von toten geliebten Personen und stellen diese der Öffentlichkeit zur Verfügung. Als Bildbetrachtende schauen wir dabei auf Gesichter von Verstorbenen, die wir als Lebende nicht gekannt haben. Valentine Godé-Darel, Susan Sontag oder Chiara haben uns nicht selbst erlaubt, ihre toten Gesichter zu betrachten. An ihre Stelle sind An- und Zugehörige getreten, die sich für die Publikation von entsprechenden Bildern

21 Elisabeth Zahnd Legnazzi: Chiara - Eine Reise ins Licht. Zürich 2009.

22 Elisabeth Zahnd Legnazzi im Gespräch mit Katrin Hafner. In: Tages-Anzeiger, o6. Mai 2009 . 
entschieden haben und die uns mit diesen Bildern entgegentreten. Das Bild ist ein Aufruf zur doppelten Anerkennung. Zum einen geht es um das Memento mori: Wir sollen dem Tod der anderen ins Auge sehen und daran erinnert werden, dass er früher oder später auch uns bevorsteht. Zum anderen geht es um die Erinnerung an die unverwechselbare, individuelle tote Person. Die autobiografische Komponente bzw. die damit verbundene Trauerbewältigung spielt hier eine zentrale Rolle.

Genau diese Komponente entfällt bei künstlerischen Darstellungen von anonymen Leichnamen, zu denen die Künstler:innen keine vorangegangene persönliche Beziehung hatten und die hier abschließend vorgestellt werden.

\section{Gegen die Totenverdrängung: Der anonyme Leichnam in der Kunst}

Bei der Arbeit mit und an anonymen Leichnamen stellen Maler:innen und Fotograf:innen Tote dar, denen sie ausschließlich als Leichen begegnen. Zentrale Anliegen solcher Arbeiten ist die Fokussierung auf Tod und Sterblichkeit: Die Künstler:innen weisen auf diese allgemeinen Themen hin, indem sie Leichname in Szene setzen, abbilden, vorführen, ausstellen. Zugang zu den Leichnamen erhalten sie in Leichenhäusern.

Die mexikanische Künstlerin Teresa Margolles (geb. 1963), diplomierte Gerichtsmedizinerin, befasst sich seit Jahrzehnten mit der anhaltenden Gewalt in Mexiko und hält sich dabei oft in Leichenhäusern auf: „Der Zustand von Leichenhäusern ist sozusagen das Thermometer einer Gesellschaft, an ihm wird ablesbar, was sich auf den Straßen draußen abspielt.“23 In ihren Arbeiten zeigt Margolles keine Leichname, jedoch verwendet sie Materialien, mit denen Leichname in Berührung gekommen sind, beispielsweise das Wasser von Leichenwaschungen, oder auch Materialien, die der tote Körper bei der Obduktion abgegeben hat, wie Fett oder Blut. So tunkt sie etwa Aquarellblätter in Wasser von Leichenwaschungen oder rührt aus solchem Wasser Beton an, den sie zu einer unscheinbaren Bank verarbeitet, auf der die Museumsbesucher:innen Platz nehmen können. Da solche Herkunft der Materialien in den Exponaten selbst nicht sichtbar ist, verweist die Künstlerin jeweils mittels sprachlicher Zusatzinformation darauf.

23 Arbeit am Leichnam. Gespräch mit Teresa Margolles. In: Corina Caduff: Wozu Vergänglichkeit? Elf Gespräche über Atome, Tod und schwarze Löcher. Berlin 2018, S. 119. Online unter: https://arbor.bfh.ch/198/1/10366_Caduff_Wozu\%2oVergaenglichkeit.pdfhttps://arbor. bfh.ch/198/1/10366_Caduff_Wozu\%2oVergaenglichkeit.pdf (letzter Zugriff: 23.11.2021). 
Bei denjenigen Künstler:innen, die anonyme Leichname unmittelbar zeigen, manifestieren sich verschiedene Praktiken in der Ausgestaltung, beispielsweise in Bezug auf die Perspektiveneinnahme und die Hintergrundgestaltung, auf das Arrangement allfälliger Requisiten oder die Verwendung von Bildvorlagen. Die Malerin Heike Ruschmeyer (geb. 1956) hat sich darauf spezialisiert, Tote nach Fotografien zu malen, welche im Leichenhaus von Kriminalist:innen und Leichenbeschauer:innen gemacht wurden. Die institutionell erstellte Totenfotografie wird damit künstlerisch weiterverarbeitet. Die Künstlerin malt die nackten toten Körper mit kräftigen Pinselstrichen nach, so dass sie gleichsam mit Farbe zugedeckt werden und die Bilder einen expressiven Charakter annehmen. Wo auf den Bildern keine Unterlagen (Bahren, Tische) kenntlich werden, könnten die Totenporträts auch als Porträts von Schlafenden wahrgenommen werden (vgl. Abb. 24 und 25) ${ }^{24}$ - Wie Ruschmeyer orientiert sich auch der junge Saarbrücker Künstler Mathias Aan't Heck (geb. 1989) an der anatomischen Studie. So verbrachte er mehrere Monate in den Sektionssälen des anatomischen Instituts der Universität des Saarlandes, um lebensgroße Bleistiftzeichnungen von Verstorbenen anzufertigen (vgl. Abb. 26 und 27).

Die von Ruschmeyer und Aan't Heck angewandte Mal- und Zeichentechnik erzeugt eine mediale Distanzierung der Leichname: Die Bilder sind auf den ersten Blick erkennbar als Kunstbilder und in diesem Rahmen gleichsam stabilisiert. Im Gegensatz zu fotorealistischen Darstellungen erzeugen sie weder voyeuristische Neugier noch Abwehr oder reflexartigen Schrecken, sondern laden vielmehr dazu ein, den Blick unaufgeregt auf der Darstellung verweilen zu lassen.

Ganz anders im Vergleich dazu nehmen sich die Leichnamsfotografien von Sue Fox (geb. 1964), Jeffrey Silverthorne (geb. 1946), Andres Serrano (geb. 1950), Sally Mann (geb. 1951) oder Cathrine Ertmann (geb. 1950) aus. ${ }^{25}$ Die Bilder sind in unterschiedlichen Leichenhäusern entstanden, wobei dies jeweils von der Verwaltung oder einzelnen institutionellen Vertreter:innen, nicht immer aber von den Angehörigen der Toten erlaubt wurde. Dementsprechend galt

24 Vgl. dazu die ältere Fotoserie von Rudolf Schäfer (geb. 1952), die 1980/81 in der Berliner Charité entstand und 1989 unter dem Titel Der ewige Schlaf. Visages de morts publiziert wurde: Die Fotos zeigen Porträts von Gesichtern mit geschlossenen Augen, sie vermitteln den Eindruck von friedlich Schlafenden und knüpfen darin an christliche Andachtsbilder an. Ohne Wissen um Bildtitel und Entstehungsgeschichte erkennt man kaum, dass es sich um Tote handelt.

25 Siehe Andres Serrano: The Morgue (1992). Tel Aviv 1996. Fotografische Arbeiten von Sue Fox und Andres Serrano in: Chris Townsend: Vile Bodies. Photography and the Crisis of Looking. München, New York 1998, S. 132f. und Plate 89-97; Jeffrey Silverthorne: Photographs. Stuttgart 1993. 
in einigen Fällen die Auflage, dass die Gesichter der fotografierten Leichname nicht erkennbar bzw. dass die Leichname nicht identifizierbar sein dürfen. Die Fotografien präsentieren aufgeschnittene Körper und obduzierte Leichname, die nach der Öffnung lediglich grob vernäht wurden, Nahaufnahmen von offenen Mündern und blutigen Körperteilen (vgl. Abb. 28 bis 30).

Eine solch direkte künstlerische Konfrontation mit toten Körpern erscheint als radikale Grenzform. Die Fotos dieser Künstler:innen machen den Leichnam, der gemeinhin außer Sicht gebracht ist, nicht nur wieder visuell zugänglich, sondern sie zeigen ihn geradezu als Kehrseite der Thanatopraxie, welche die Toten so schön wie möglich erscheinen lässt. Hier wird der tote Körper als Objekt der Pathologie präsentiert: geöffnet, verschmiert, verunstaltet, achtlos liegen gelassen. Die Bilder lassen sich somit zur Abject Art rechnen, welche Ekel oder Abwendung auslöst und gemeinhin in der Konfrontation mit instabiler organischer Materie - z. B. Menstruationsblut, Kot, undefinierbare Weichteile sowie eben auch Leichname - besteht. ${ }^{26}$

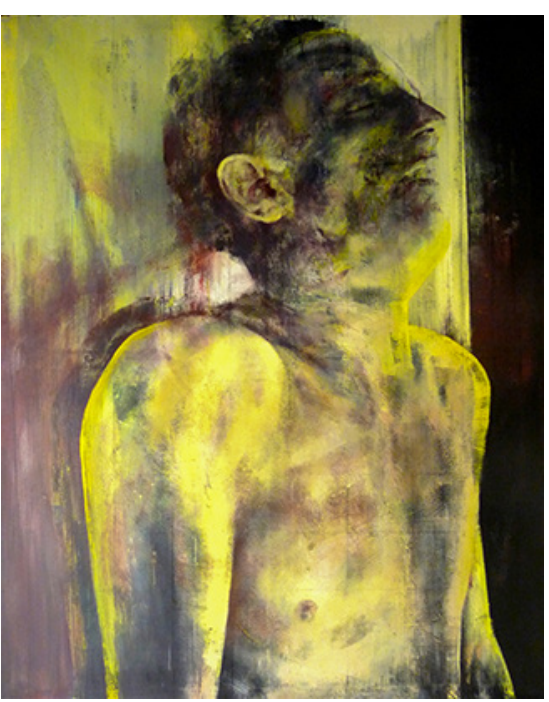

Abb. 24

Heike Ruschmeyer: Monolog XXVII, 1988, Kunstharz, Eitempera und Ölfarbe auf Nessel, $240 \mathrm{~cm} \times 190 \mathrm{~cm}$, fotografiert von Jan Schüler. Online unter: https://commons. wikimedia.org/wiki/File:MonologXXVIII.jpg, Lizenz: CC-BY-SA (letzter Zugriff: 23.11.2021).

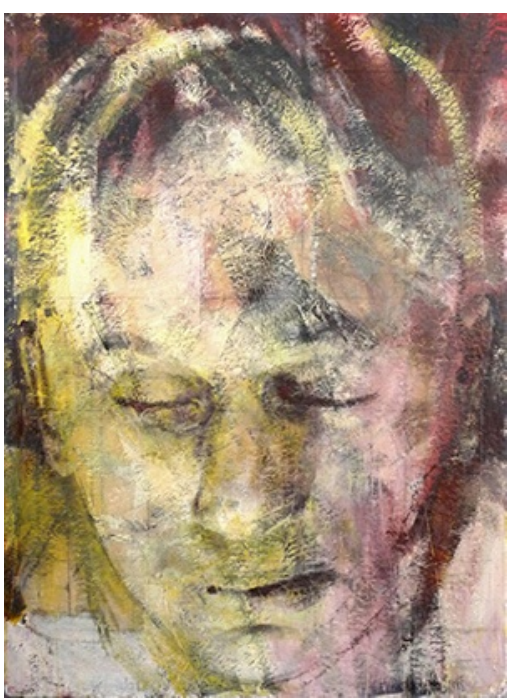

Abb. 25

Heike Ruschmeyer: Monolog XCVII, 1995, Kunstharz, Eitempera, Ölfarbe, Stoff auf Dämmpappe, $180 \mathrm{~cm} \times 13^{2} \mathrm{~cm}$, fotografiert von Jan Schüler. Online unter: https://commons.wikimedia.org/wiki/ File:MonologXCVII.jpg, Lizenz: CC-BY-SA (letzter Zugriff: 23.11.2021).

26 Den Begriff abjection geprägt hat die französische Literaturtheoretikerin und Psychoanalytikerin Julia Kristeva: Pouvoirs de l'horreur. Essai sur l'abjection. Paris 1980. In der Kunstszene wurde er durch die Ausstellung Abject Art. Repulsion and Desire in American Art (1993) im Whitney Museum of American Art in New York in Umlauf gebracht. 


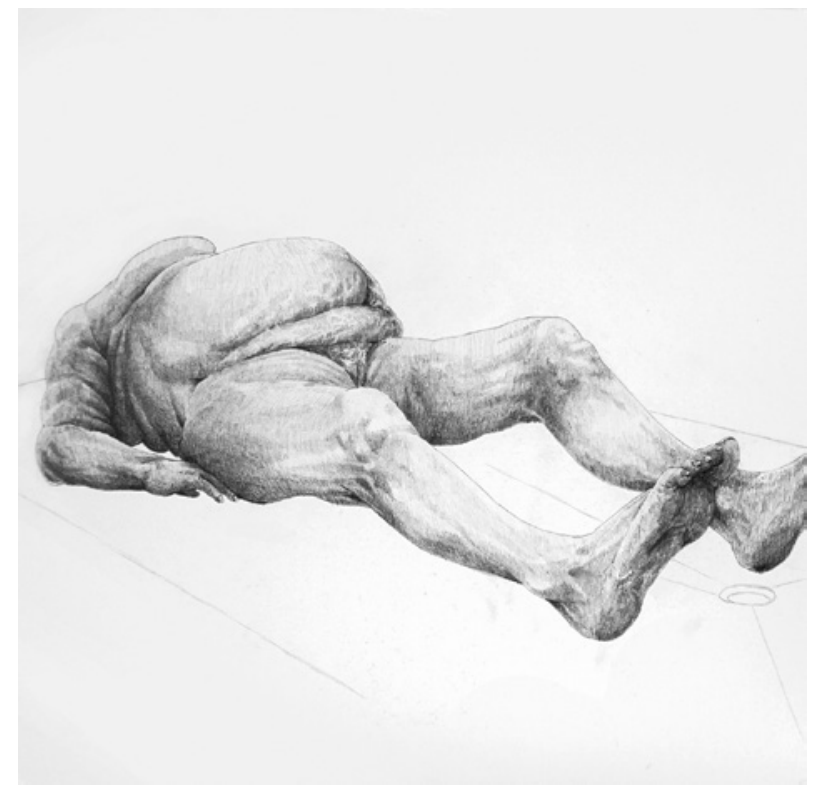

Abb. 26 Mathias Aan't Heck: 1855 Studie II, 202O. Bleistift auf Papier, 29,7 cm × 29,7 cm. (C) Mathias Aan't Heck. Mit freundlicher Genehmigung des Künstlers.

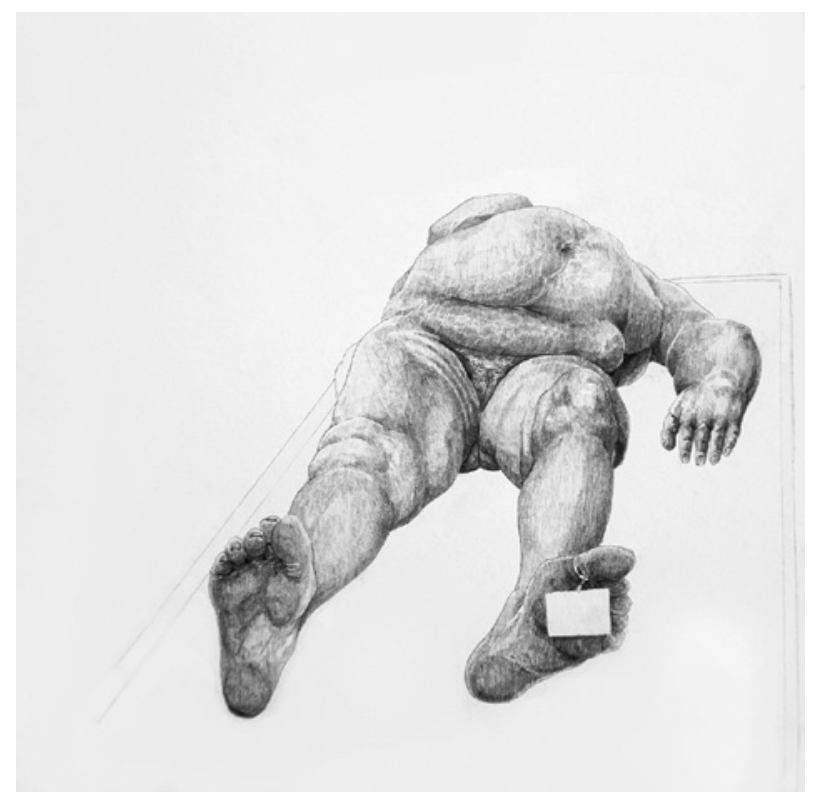

Abb. 27 Mathias Aan't Heck: 1855 Studie I, 2020. Bleistift auf Papier, 29,7 cm × 29,7 cm. (C) Mathias Aan't Heck. Mit freundlicher Genehmigung des Künstlers. 

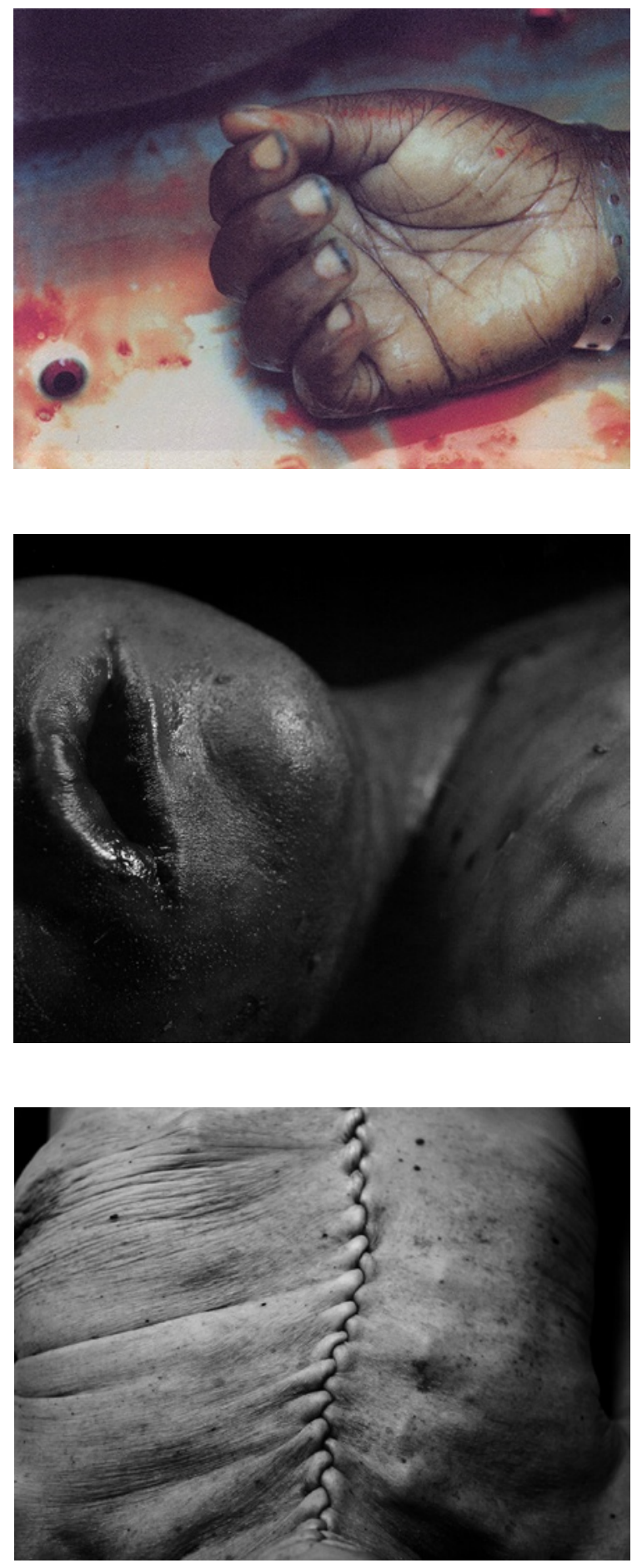

Abb. 28

Sue Fox, Life Line, 1993. Farbfotografie, $15 \mathrm{~cm} \times 10 \mathrm{~cm}$, Privatsammlung. In: Thomas Macho, Kristin Marek: Die neue Sichtbarkeit des Todes. München 2007, S. 119. Mit freundlicher Genehmigung der Künstlerin.

Abb. 29

Andres Serrano: The Morgue (Death by Drowning II), 1992. In: Ders.: fotografiska arbeten $=$ works 1983-1993. Malmö 1996, S. 124.

Abb. 3o: Cathrine Ertmann: About Dying, 2012. Online unter: https://www. cathrineertmann.dk/ aboutdying (letzter Zugriff: 23.11.2021). 
Insbesondere Leichen-Fotografien der britischen Fotografin Sue Fox erzeugen Schrecken oder gar Schockmomente, vor allem beim erstmaligen Anschauen. Die Fotografie Inside Out (1996, Abb. 31) beispielsweise zeigt Reste eines aufgeschnittenen Körpers, mit zur Seite gefallenen Hautlappen, aus denen die Rippen hervorstechen. Der Kopf ist nach rechts gedreht, die Kopfhaut abgezogen, so dass man nur den blutverschmierten Schädel sieht. Möglicherweise hatte die verstorbene Person einen Genickbruch erlitten. ${ }^{27}$ Das Skandalon dieser Abbildung besteht darin, dass sie kaum Assoziationsräume ermöglicht: Man denkt nicht unmittelbar an andere, vergleichbare Bildwelten, die man schon kennt, man stellt keine Kontexte her, es eröffnen sich keine Referenzfelder. Künstlerische Produkte leben im Allgemeinen davon, dass sie aufgeladen werden durch das Denken und Wissen, durch die Intuition und Sinnlichkeit der sie betrachtenden Personen, sie leben davon, dass ihnen etwas entgegengebracht wird, dass sie geortet und gedeutet werden und sich auf diese Weise im Dialog mit den Betrachtenden erfüllen. Eine solche lebendige Betrachtung aber ist kaum möglich, wenn wir schockartig mit Bildern konfrontiert sind, die uns etwas zeigen, das uns gänzlich neu ist und das wir gemeinhin reflexartig abwehren.

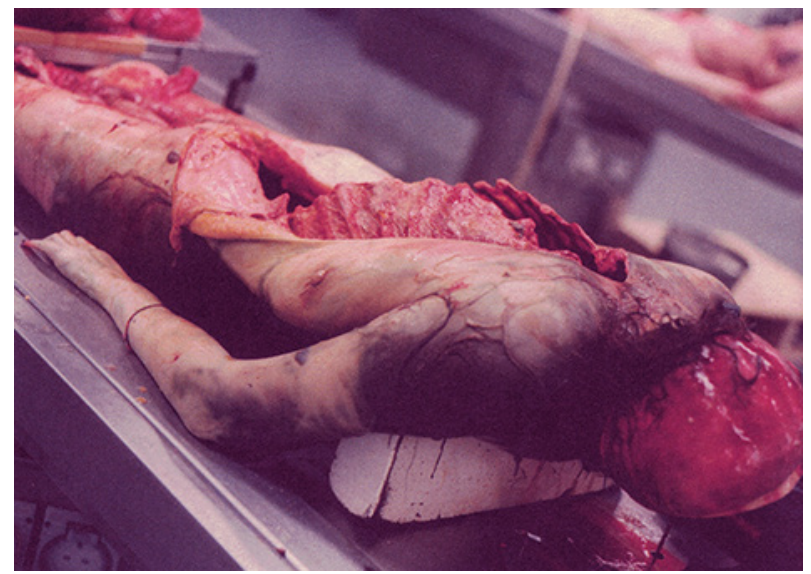

Abb. 31 Sue Fox: Inside Out, 1996. Farbfotografie, 12,7 cm × $17,7 \mathrm{~cm}$, Privatsammlung. In: Thomas Macho, Kristin Marek: Die neue Sichtbarkeit des Todes. München 2007, S. 124. Mit freundlicher Genehmigung der Künstlerin.

Sue Fox selbst hält zu ihrer Tätigkeit fest: „Indem ich die Toten betrachte, setze ich mich einer der größten Ängste aus, der Angst vor Selbstvernichtung, vor

27 Mit Dank für den Hinweis an Roland Kunz, bis 2021 Ärztlicher Leiter des Zentrums für Palliative Care, Stadtspital Waid und Triemli Zürich. 
Verfall und Sterben. Ich versuche, mein Bewusstsein zu erweitern, indem ich diese Ansichten in mich aufnehme.“28 - Einer vergleichbaren Ausrichtung folgen die Totenfotografien von Sally Mann. Die US-amerikanische Fotografin erhielt von der University of Tennessee in Knoxville die Möglichkeit, im Rahmen von Forschungstätigkeiten verwesende Leichname zu fotografieren. Diese waren vom Institut für forensische Anthropologie im Außenraum abgelegt worden, wo sie über längere Zeit liegengelassen wurden, um natürliche Verwesungsprozesse zu erforschen. Dort konnte Sally Mann sie fotografieren (vgl. Abb. 32) ${ }^{29}$

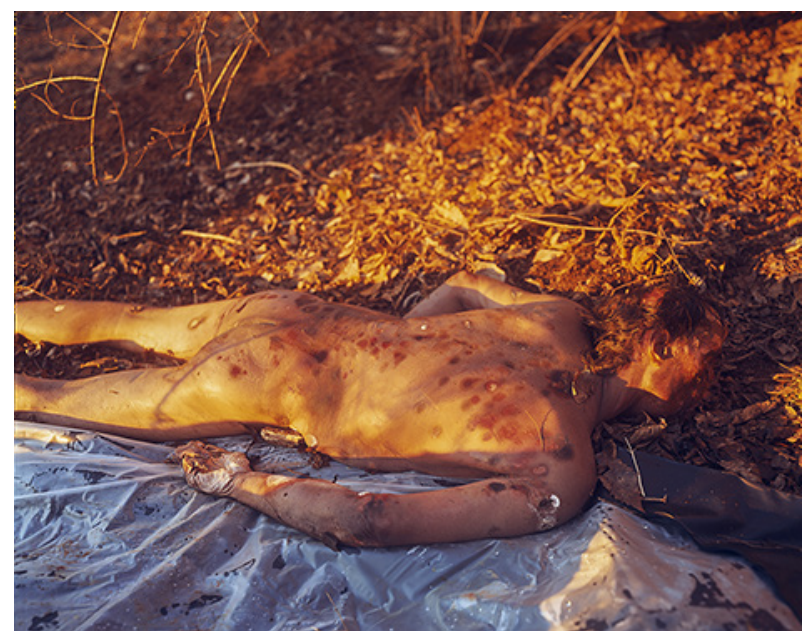

Abb. $3^{2}$ Sally Mann: Untitled, 20oo. Gelatinesilberdruck, 30 in $\times 38$ in. (C) Sally Mann. Mit freundlicher Genehmigung der Gagosian Gallery, New York.

Allgemein leistet die Darstellung von anonymen Leichnamen keine spezifische Trauerarbeit, und sie dient auch nicht der Erinnerung an bestimmte Personen. Die Toten haben keine Biografien, es wird nichts über sie erzählt, außer dass sie in der Leichenhalle liegen. So ist es auch kaum möglich, anhand der Leichname (Lebens-)Geschichten der entsprechenden Personen zu rekonstruieren oder zu imaginieren. Was man sieht, ist lediglich ein Rest, die bloße Anschauung von Leichnamen, die keinerlei Bedeutung aufwirft als eben jene, dass es sich um einen anonymen Leichnam aus der Pathologie handelt.

28 Sue Fox: „Kontemplationen zum Leichnam“. In: Thomas Macho, Kristin Marek (Hg.): Die neue Sichtbarkeit des Todes. München 2007, S. 105.

29 Die Fotografie gehört zur Serie Body Farm, vgl. dazu weitere Fotos, https://www.sallymann. com/body-farm/ (letzter Zugriff: 23.11.2021), sowie Eleanor Heartney: „Photography IN. The Forensic Eye“. In: Art in America 93/1 (2005), S. 50-55. 
Das Potenzial solcher in Totenhäusern entstandenen künstlerischen Leichenbilder liegt im Gegensatz zur fotografischen Abbildung von geliebten Toten genau darin, dass sie den Leichnam nicht als Individuum inszenieren, sondern ihn gezielt und einzig als Memento mori einsetzen und sich damit gegen die allgemeine physische und psychische Verdrängung und Vernachlässigung von Toten richten.

Explizit thematisiert wird eine derartige Vernachlässigung von der thailändischen Künstlerin Araya Rasdjarmrearnsook (geb. 1957). Sie befasst sich in ihren verschiedenen Arbeiten insbesondere mit Toten, Tieren und psychisch kranken Menschen, wobei sie jeweils die versperrte sprachliche Kommunikation künstlerisch bearbeitet. 2005 führte sie Video-Performances mit Toten durch, die unter Ausschluss der Öffentlichkeit in der Leichenhalle eines Krankenhauses stattfanden (The Class und Conversation I). Dabei handelte es sich um Tote, die keine Angehörigen mehr hatten. Während der Performances lagen sie auf Metallbahren auf dem Boden, mit weißen Laken bedeckt. Die Künstlerin sprach vor ihnen über mögliche Verbindungen zwischen Lebenden und Toten, über mögliche Lebensformen im Jenseits, und sie vollzog singend und summend Bestandteile von Totenritualen des Theravada Buddhismus (vgl. Abb. 33 und 34).

Mit diesen Video-Performances kritisiert Rasdjarmrearnsook den Verlust an Bindung zwischen Toten und Lebenden. Indem sie die unbeachteten Toten selbst sichtbar macht, anspricht und ins Bild rückt, sucht sie sie zu bewahren und ihnen eine Präsenz zu geben: „In reality, life and death should not be understood as opposites. People deal with death by trying to hide it. They hide death behind ritual or hope to prevent it with medicine. I want people to have more imagination and confront reality!"30

Wir sind weder den Anblick noch die Vorstellung von Leichnamen gewohnt. Wo wir als Hinterbliebene doch in Einzelfällen am offenen Sarg stehen, werden die Verstorbenen für genau diesen letzten Blick hergerichtet. Die genannten Künstler:innen hingegen inszenieren die Toten anders, denn ihre Bilder sind nicht für Hinterbliebene gedacht. Sie anzuschauen bedeutet eine Ausweitung unseres Sehens und unserer Wahrnehmung; eine Ausweitung, die das Bewusstsein von Sterblichkeit wachhält und Blicke in die Kellerräume der Pathologie ermöglicht. Zugleich bringt diese Form der Betrachtung auch eine tiefe Irritation mit sich: Man fühlt sich durch den Anblick der Leichnamsbilder

30 Araya Rasdjarmrearnsook im Interview mit Brian Curtin, 2007. "Confronting Confrontation“. Online unter: http://www.trfineart.com/wp-content/uploads/2016/11/ArtSignal-2007-Confronting-Confrontation-An-Interview-with-Araya-Rasdjarmrearnsook-.pdf (letzter Zugriff: 23.11.2021). 

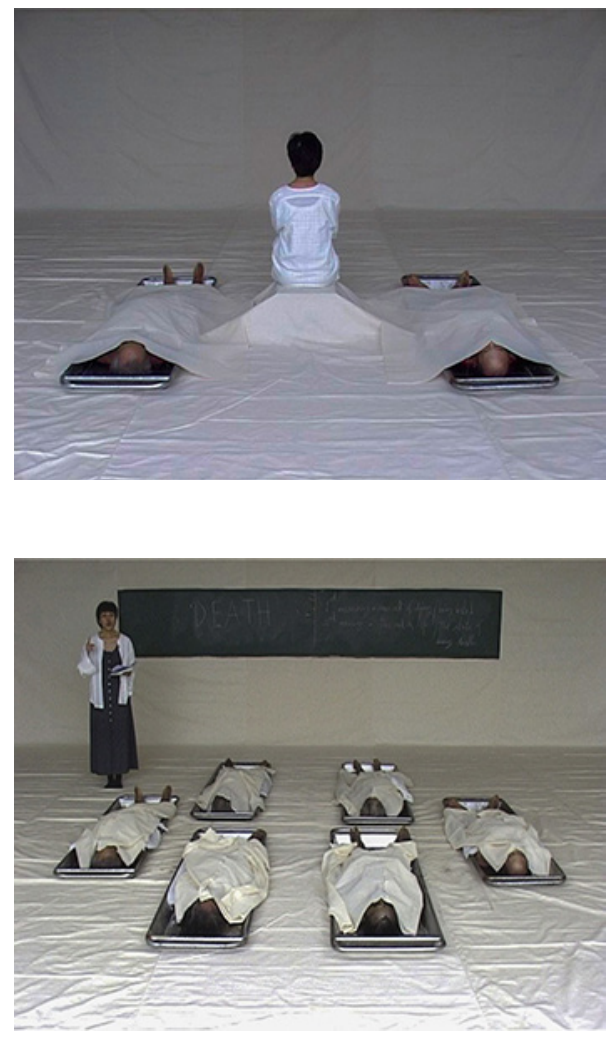

Abb. 33

Araya Rasdjarmrearnsook: The Class, 2005. Video, 16 Min. 25 Sek., Mori Art Museum. Online unter: https://www. mori.art.museum/en/collection/2337/ index.html (letzter Zugriff: 23.11.2021).

Abb. 34

Araya Rasdjarmrearnsook: Conversation I, 2005. Video-Installation, 13 Min. 30 Sek., FRAC Nord-Pas de Calais, Dünkirchen. Online unter: https://www.hfcollection. org/conversation-i-iii/ (letzter Zugriff: 23.11.2021).

in den eigenen (Körper-)Grenzen existenziell verunsichert, denn es geht immer auch um die Tatsache, dass wir alle selbst eines Tages zu einem Leichnam werden.

So bewegen sich realistische Leichenbilder an einer Schwelle, an einer Grenze des Erträglichen. Folglich mögen sie als makabres Skandalon erscheinen, weil sie mit ungewohnten Sichtweisen normierte Grenzen überschreiten. An dieser Grenze erschallt Kritik an der Darstellung. Entsprechende Vorwürfe - Missbrauch von Toten, kranke Künstler, hinterhältige Art des Fotografierens - ziehen sich wie ein roter Faden durch die Rezensionen entsprechender Ausstellungen. ${ }^{31}$

31 Sue Fox berichtet, dass Museumsbesucher:innen angesichts ihrer Fotos in einem ausgelegten Kommentarbuch sie des Missbrauchs von Toten angeklagt und persönlich pathologisiert hätten - „you're sick“, „you've got problems“; siehe dazu Ann Treneman: „Visual Arts: Vile Bodies?“ In: The Independent, 24. März 1998. Zur Kritik an Rasdjarmrearnsook und Serrano siehe Mary O'Neill: „Speaking to the Dead: Images of the Dead in Contemporary Art“. In: Health 15/3 (2011), S. 304-306. 


\section{„Angriff auf das eigene Leben“}

Totenbilder sind annehmbar und nicht unmittelbar angreifend, solange sie dem Betrachtenden keine Pein zufügen. Dies gilt insbesondere für die fiktiven Leichen der Unterhaltungsindustrie sowie teilweise auch für gemalte Kunstbilder von anonymen Leichnamen, die tendenziell friedlich anmuten. Bei konkreten erkennbaren Personen jedoch, auch wenn diese ,schön inszeniert sind wie im Falle von Susan Sontag, kommt Kritik auf, die sich auf den Schutz der Privatsphäre und auf verletzte Persönlichkeitsrechte der dargestellten Toten bezieht. Ebenfalls beanstandet werden fotorealistische Darstellungen von anonymen Leichnamen, aber diese Kritik ist anders gelagert, denn sie sucht nicht das verletzte Recht einer toten Person geltend zu machen, sondern vielmehr das Recht auf Unversehrtheit derjenigen Person, die das Bild betrachtet. Wie Hoffmann und Tietjen in der Einführung zu Das letzte Bild. Fotografie und Tod festhalten, kann die Präsentation „des geschundenen, zu einem leblosen Ding geronnenen Körpers als Angriff auf das eigene Leben verstanden und dementsprechend abgewehrt werden. ${ }^{32}$

Je mehr imaginative Antizipation der eigenen Sterblichkeit durch Bilder hervorgerufen wird, umso stärker kann man diese als Angriff auf das eigene Leben empfinden und umso stärker mag eine unmittelbare Abwehr erfolgen; im günstigen Falle aber setzt man sich mit den Gründen dieser Abwehr bzw. mit der eigenen Sterblichkeit auseinander und genau dies kann zu einer verstärkten Zuwendung zu den Bildern führen. Dabei kann es jedoch nicht darum gehen, einen bestimmten Umgang mit dem Leichnam zu verordnen, es kann nicht um den Imperativ gehen: Befasse dich mit deiner eigenen Sterblichkeit, schau ihr in die Augen, geh hin zu dem Leichnam und sieh ihn dir an. Auf jeden Fall aber geht es darum, den unterschiedlichen Umgangsweisen mit Leichnamen Beachtung zu schenken und das Streben nach entsprechend diversen Darstellungsformen anzuerkennen und zu ermöglichen. Die große Leistung der Künstler:innen, die dem Publikum solche Bilder zumuten, besteht in der Insistenz, den Blick auf reale Leichname freizulegen und damit aufzuzeigen, wie prekär, wie abgedrängt die Repräsentation der Toten heute in unserer Kultur ist. 